\title{
Antimicrobial Activity and Phytochemical Study of Plant Parts of Butea monosperma
}

\author{
Kruti Dave ${ }^{1 *}$, Parth Darji², Fenie Gandhi ${ }^{3}$, \\ Mehsana Urban Institute of Sciences, Ganpat University, Gujarat, India 1,2,3
}

\begin{abstract}
Since ancient times, plants have been model source of medicines as they are a reservoir of chemical agents with therapeutic properties. The general population is increasingly using herbal medicines as dietary supplements to relieve and treat many different human disorders. All parts of the plant, from root to fruit, consisting of a multitude of secondary metabolites which impart an unprecedented variety of medicinal uses to the plant. Studies have shown the presence of different phytochemical constituents in botanical sample responsible for the antimicrobial activity. These antimicrobial agents should be beneficial to host cells and toxic to pathogenic microbes. Hence, the antibacterial activity was examined from the leaf and flower of Butea monosperma. Sample was collected and its crude extract was obtained by using methanol, acetone and water as the extraction solvent. These extract were tested against some pathogenic microorganisms like Staphylococcus aureus , Bacillus cereusa and B. subtilis. The extract of Butea monosperma showed antibacterial activity against Staphylococcus aureus, Bacillus cereusa and B. subtilis. Bio-chemical test for the presence of phytochemicals have shown positive result and these phytochemicals have ability to fight against microorganisms or inhibit the growth of microorganisms. This approach will be an advanced step in the discovery of some herbal drugs. These plant extracts which was proven to be potentially effective can be used as a natural alternative to the chemical preservatives. It could be an ideal way to avoid health hazards that may occur due to chemical antimicrobial agents.
\end{abstract}

Keywords: Antibacterial activity, phytochemical analysis, Plant Extract, Butea monosperma

Article Info: Received 03 July 2019; Review Completed 20 Aug 2019; Accepted 26 Aug 2019; Available online 30 Aug 2019

\section{Cite this article as:}

Dave K, Parth D, Gandhi F, Antimicrobial Activity and Phytochemical Study of Plant Parts of Butea monosperma, Journal of Drug Delivery and Therapeutics. 2019; 9(4-A):344-348 http://dx.doi.org/10.22270/jddt.v9i4-A.3435

*Address for Correspondence:

Kruti Dave, Mehsana Urban Institute of Sciences, Ganpat University, Gujarat, India 1,2,3

\section{INTRODUCTION:}

Medicinal plants contain plentiful active ingredients that may be potentially useful for the development of therapeutic agents. The identification and isolation of phytochemical groups and/or single chemical entities from them are, therefore, crucial for drug discovery as these entities often work as individual agents or as a collective group of phytocompounds (purified extracts) to achieve the desired therapeutic effect. However, to evaluate their quality, standardisation of these plant parts needs to be carried out, which includes a series of tests to determine the quality, quantity and the purity of the phytocompounds. ${ }^{1}$ Butea monosperma is taken into consideration for this experiment.

Butea monosperma (Lam.) is commonly known as Flame of forest, belongs to the family Fabaceae. It is locally called as palas, palash, mutthuga, kesudo, bijasneha, dhak, khakara, chichra, Bastard Teak, Bengal Kino, Nourouc and is common throughout India, Burma and Ceylon except in very acrid parts. Generally it grows gregariously on open grass lands and scattered in mixed forest. Plantations can be raised both on irrigated and dry lands. The pods should be collected and sown before the commencement of rains as they grow best under high temperature and relative humidity, root suckers are freely produced and help in vegetative propagation. In India, palas ranks next to kusum (schleichera trijuga) as a host tree for lac insect. Almost all the parts of the plant are being utilized since decades in medicine and for other purposes. These days herbal medicines are more trendy than modern medicine because of their effectiveness, easy availability, low cost and for being comparatively devoid of side effects. Nature always stands a golden mark to exemplify the outstanding phenomenon of symbiosis and it has granted the storehouse of remedies to cure all ailments of mankind, only the thing is that there is a need to evaluate them scientifically. 2,3,4

An erect tree 12-15 m high with crooked trunk and irregular branches, bark rough, ash coloured, young parts downy. Leaves 3-foliate, petioles 10-15 cm long, stipules linearlanceolate. Leaflets coriaceous (the terminal $10-20 \mathrm{~cm}$ long, broadly ovate from a cuneate base, the lateral smaller, 10-15 by $7.5-10 \mathrm{~cm}$, obliquely rounded at the base, equilateral, the lower side the larger), all obtuse, glabrous above when old, finely silky and conspicuously reticulately veined beneath; petioles $6 \mathrm{~mm}$ long, stout-stipels subulate, deciduous. Flowers large, in a rigid racemes $15 \mathrm{~cm}$ long, 3 
flowers together form the tumid nodes of the dark olivegreen velvety rhachis: pedicels about twice as long as the calyx, densely brown-velvety: bracts and bracteoles small, deciduous. Calyx $13 \mathrm{~mm}$ long, dark olive-green, densely velvety outside, clothed with silky hairs within: teeth short, the 2 upper connate, the 3 lower equal, deltoid. Corolla 3.8-5 $\mathrm{cm}$ long, clothed outside with silky, silvery hairs, orange or salmon coloured: standard $2.5 \mathrm{~cm}$ broad: keel semi-circular, beaked, veined. Pods stalked $12.5-20$ by $2.5-5 \mathrm{~cm}$, thickened at the sutures, reticulately veined argenteo-canescent: stalked $2 \mathrm{~cm}$ long .5,6

Butea monosperma (BM), also known as Palas in the traditional system of medicine is a medicinal plant. As reported by the Indian Ayurvedic texts, its leaves, stem, flowers, seeds, gum (stem) and roots have been widely used as traditional ayurvedic medicine. Its classification is presented in Table 1.

Food-borne illness caused by eating food or drinking beverage contaminated with bacteria, parasites or viruses, can cause symptoms that range from an upset stomach to more serious symptoms such as diarrhea, fever, vomiting, abdominal cramps and dehydration. ${ }^{7}$

Foodborne pathogens are of public health concern worldwide. Estimates of the total number of foodborne illnesses and associated hospitalizations and deaths are needed to figure out their effect on health and to set priorities for surveillance, prevention, and control strategies. ${ }^{8}$

To control this type of microorganisms we take synthetic antibiotics like Ampicillin, Cefixine,

Amoxicillin-clavulanate, Tetracycline, Clarithromicine, Azithromycin, Erythromycin, Fluoroquinolones, Cephalosporins, Penicillins,etc. But because of theses antibiotics, side effects like Antibiotic associated diarrhea, Allergic reactions - Anaphylaxis, Toxic Epidermal Necrolysis (TEN), Stvens-Johson Syndrome (SJS), Diarrhea, Bloody diarrhea, Vomiting, Serious and Rare allergic reaction, Mucous membrane and Skin disorder, etc may produce.

Plants have been a source of medicinal treatments for eons, and phytotherapy continue to play a fundamental role in primary health care of about $80 \%$ of the world's underdeveloped and developing countries. The trend of using complementary and alternative medicines (CAM) has expanded in recent years both in the developing and developed countries. Due to limited research, findings on proving safety and efficacy of CAM are scarce. Hence, time demands pharmacological profiling of such drugs in order to identify the ones that are truly effective.

Furthermore, the demand for medicinal plants is increasing due to recognition of natural products being non-narcotic, non-toxic with no side effects, easy availability, cost effectiveness and often in numerous cases being the only source of health care for the poor. So by review of history and previous documentation, it is an attempt to detect the compound responsible for specific pharmacological activity. To isolate, characterize the compound and monitor the activity of prime importance. ${ }^{9}$

Butea monosperma as astringent, antidiarrheal, antidysenteric, febrifuge aphrodisiac purgative antihelmintic properties. It is used for timber, resin, fodder, medicine, and dye. the Phytoconstituents from the extract of the flower: Butein, butrin, iso butrin, and isocoreopsin were noted to have inhibitory activity against inflammatory gene expression; its flower extract with its isolated content rutin was reported for antioxidant activity; the methanolic extract of the flowers and its isolated phytochemicals isobutrin and butrin were reported as having anti-inflammatory, anticonvulsant activities and antidiabetic, hepatoprotective effects. 10

Keeping this in view, present study was carried out to evaluate phytochemical and antimicrobial activity of Butea monosperma.

Table: 1 Scientific classification of Butea monosperma.

\begin{tabular}{|c|c|}
\hline Kingdom & Plantae \\
\hline Sub kingdom & Tracheobionta \\
\hline Division & Magnoliophyta \\
\hline Class & Magnoliopsida \\
\hline Subclass & Rosidae \\
\hline Order & Fabales \\
\hline Family & Fabaceae \\
\hline Genus & Butea \\
\hline Species & Monosperma \\
\hline
\end{tabular}

\section{MATERIALS AND METHODS:}

\section{Plant materials and Bacterial strain}

Leaves and Flowers of Butea monosperma were used as plant material for preparation of extract. The antibacterial activity of each plant extract was estimated using three bacterial strains causing food poisoning diseases, were of Gram positive (Staphylococcus aureus, Bacillus cereus and B. subtilis) bacteria.

\section{Preparation of plant extracts}

The plant materials of Butea monosperma were collected, disinfected, water washed, and dried under a shade. The dried plant material of each plant species was ground using mortar and pestle to obtain fine powder and then was passed through $1.00 \mathrm{~mm}$ sieve.

10 gram fine powder of each plant was soaked in $100 \mathrm{ml}$ of different solvents such as methanol, acetone and Water separately for 48 hours followed by loading in soxhlet apparatus and subject to continuous extraction (4-5 hours) with respective solvents to obtain crude extracts. There after the solvent (acetone, methanol and water) was removed under reduced pressure using rotatory vacuum evaporator. The concentrated residues were dissolved in dimethyl sulphoxide (DMSO; $10 \% \mathrm{w} / \mathrm{v}$ ) and stored at $4^{\circ} \mathrm{C}$ until use. The extract yields were weighted and stored in small bottles in refrigerator at $4^{\circ} \mathrm{C} .11$

\section{Evaluation of antimicrobial activities of plant extracts}

Antimicrobial activity of plant extracts was analysed by Well diffusion method. About $20 \mathrm{ml}$ nutrient (base) agar was plated in petri dishes and allowed to solidify for 30 minutes. The test microorganisms such as Bacillus cereus, Staphylococcus aureus were seeded $(0.1 \mathrm{ml}$ : 107108cells $/ \mathrm{ml}$ ) into sterile molten nutrient soft agar medium which was overlaid on the nutrient agar base. The Well ( 5 mm diameter) were formed on the surface of the seeded agar plates. Proceeded by the plant extract of Butea monosperma were loaded in to well $(50 \mathrm{mg} / \mathrm{ml}) \cdot 10 \mu \mathrm{l}$ of DMSO (Dimethyl sulphoxide) was used as negative control and antibiotics like Ampicillin and Ciprofloxacin $(10 \mu \mathrm{g} / \mathrm{ml})$ were used as positive control. These plates were incubated at $37^{\circ} \mathrm{C}$ for $24-48$ hours to allow maximum growth of the microorganism. After incubation, the plates were observed for clear, distinct zone of inhibition surrounding the Well. The diameter $(\mathrm{mm})$ of zone of inhibition produced by the extract was measured and compared with the standard. All assays performed in triplicates to consider mean values as a standard one. [11] 


\section{Phytochemical analysis of plant extract:}

\section{Test for alkaloids}

$1 \mathrm{ml}$ of the extract was stirred with $5 \mathrm{ml}$ of $1 \%$ aqueous $\mathrm{HCl}$ on a steam bath and filtered while hot. Distilled water was added to the residue and $1 \mathrm{ml}$ of the filtrate was treated with a few drops of either Mayer's reagent (Potassium mercuric iodide- solution) or Wagner's reagent (solution of iodine in Potassium iodide) or Dragendorff's reagent (solution of Potassium bismuth iodide). The formation of a cream colour with Mayer's reagent and reddish-brown precipitate with Wagner's and Dragendorff's reagent give a positive test for alkaloids. ${ }^{12}$

\section{Test for Tannins}

About $1 \mathrm{ml}$ extract (Conc. 10\%w/v) was mixed in $3 \mathrm{ml}$ water and heated on boiling water for 5 minutes and then filtered. Further, $1 \mathrm{ml}$ of $0.1 \%$ ferric chloride was added to $3 \mathrm{ml}$ filtrate and observed for the appearance of dark green color or blue- black color. The appearance of this color indicates the presence of tannins. ${ }^{12}$

Test of Flavonoids: $3 \mathrm{ml}$ of $1 \%$ Aluminium chloride solution was added to $5 \mathrm{ml}$ of each extract. A yellow coloration was observed indicating the presence of flavonoids. $5 \mathrm{ml}$ of dilute ammonia solution was added to the above mixture followed by addition of concentrated $\mathrm{H}_{2} \mathrm{SO}_{4}$. By adding it , the yellow coloration disappears which indicates the presence of flavonoids, thus, indicating the test positive for flavonoids. ${ }^{12}$

Test for Saponin: About $5 \mathrm{ml}$ of the extract was boiled in $20 \mathrm{ml}$ of distilled water in a water bath and filtered. $10 \mathrm{ml}$ of the filterate was mixed with $5 \mathrm{ml}$ of distilled water and shaken vigorously for a stable persistent froth. The frothing was mixed with 3 drops of olive oil and shaken vigorously, then observed for the formation of emulsion which confirms a positive presence of Saponin. ${ }^{12}$

Phenol: $5 \mathrm{ml}$ of the extract was pipetted into a $30 \mathrm{ml}$ test tube, then $10 \mathrm{ml}$ of distilled water was added with $2 \mathrm{ml}$ of ammonium hydroxide solution and $5 \mathrm{ml}$ of concentrated amyl alcohol and left to react for $30 \mathrm{~min}$. Development of bluish green colour indicates the presence of phenols, resulting into the positive test. 12

Test for Glycosides: To $1 \mathrm{ml}$ of each extract, $0.5 \mathrm{ml}$ of glacial acetic acid and 3 drops of $1 \%$ aqueous ferric chloride solution were added, formation of brown ring at the interface indicates the presence of cardiac glycosides in the sample extract. 12

Test for Proteins: To $2 \mathrm{ml}$ of each extract, $1 \mathrm{ml}$ of $40 \%$ sodium hydroxide and few drops of $1 \%$ copper sulphate were added; formation of violet colour indicates the presence of peptide linkage molecules in the sample extract. 13

Test for Carbohydrates: Take $1 \mathrm{ml}$ of extract, add few drops of Molisch's reagent and then add $1 \mathrm{ml}$ of concentrated sulphuric acid at the side of the tubes. The mixture was then allowed to stand for 2 to 3 minutes after which the appearance of red or dull violet colour is observed which indicates the presence of carbohydrates in the sample extract. 13

\section{Determination of Activity Index (AI)}

Activity index of all the extracts was calculated using following formula14
Activity Index $(A I)=\frac{\text { Inhibition Zone of the Sample }}{\text { Inhibition Zone of the Standard }}$

\section{Determination of relative percentage inhibition (RPI)}

The relative percentage inhibition of all the test extracts with respect to the positive control was calculated by using the following formula .

$$
R P I=\frac{100(\mathrm{X}-\mathrm{Y})}{(\mathrm{Z}-\mathrm{Y})}
$$

Where $\mathrm{X}=$ Total area of inhibition of the test extract; $\mathrm{Y}=$ Total area of inhibition of the solvent and $\mathrm{Z}=$ Total area of inhibition of the standard drug.

The total area of the inhibition was calculated by using the area $=\pi r 2$; where $r=$ radius of the zone of inhibition.

\section{RESULTS AND DISCUSSION:}

Infectious diseases are the main cause of mortality worldwide. The number of multidrug-resistant microbial strains and strains with reduced susceptibility to antibiotics are continuously increasing due to indiscriminate use of antibiotics, the toxicity caused by their excessive usage causing fatal or non-fatal diseases and other synthetic antibacterial agents in treatment. ${ }^{15,16}$

Plants used in traditional medicine contain a vast array of substances that can be utilized to treat chronic and even infectious diseases. More than $80 \%$ of world's populations depend on traditional medicines derived from plants for their primary health care needs. The plant-based traditional medicines were proven highly effective for their utilization as a source of antimicrobial compounds, also usage of these medicines has shown very less to null side effects. Plants are rich in a wide variety of secondary metabolites also known as phytochemicals such as terpenoid, tannins, alkaloids, and flavonoids, which have been found to have medicinal properties. ${ }^{17}$ The medicinal and antimicrobial properties of such secondary metabolites are examined against microorganisms causing food-borne diseases in humans.

Agar well diffusion techniques have been widely utilized to assay the antimicrobial activity of plant extracts. Here, Antimicrobial activity (in terms of the zone of inhibition) of the extracts was evaluated against selected pathogenic bacterial strains by agar well diffusion method. In the present investigation, total three extracts viz., methanol, acetone and aqueous extracts of Butea monosperma leaves and flower with a concentration of $50 \mathrm{mg} / \mathrm{ml}$ were tried. ${ }^{18}$

The extracts of Butea monosperma and antibiotics as positive control showed varying degrees of antimicrobial activity against the different test organisms (Table 2) while there was no inhibition of growth with the control (DMSO) as it used as negative control.

Methanolic extract showed higher zone of inhibition against different test organisms in a rage of $17.05-22.0 \mathrm{~mm}$. it was observed that methanolic extract exhibited significant higher antibacterial activity against all test organisms as compared to acetonic and aqueous extract. In addition, extract yield in methanol solvent was significantly higher; therefore it may enhance the solubility of active components of Butea monosperma which resulted in higher antimicrobial activity compared to acetone extract. Plants extracts (methanolic, acetonic and water) of Butea monosperma showed comparative elevated antimicrobial activity against $B$. subtilis followed by B.cerus and $S$. aureus . 
Table 2: Antibacterial activity (ZOI) for ethanol and methanol extracts of different plant parts of Butea monosperma.

\begin{tabular}{|c|c|c|c|c|c|}
\hline \multirow{2}{*}{$\begin{array}{c}\text { PLANT } \\
\text { PART }\end{array}$} & EXTRACT & Concentration & \multicolumn{3}{|c|}{ Zone of Inhibition (mm) } \\
\hline \multirow{3}{*}{ Flower } & Methanol Extract & $(\mathrm{mg} / \mathrm{ml})$ & S. aureus & B.cerus & B. subtilis \\
& Acetone Extract & 50 & $17 \pm 0.5$ & $21 \pm 0.45$ & $22 \pm 0.5$ \\
& Aqueous Extract & 50 & $15 \pm 0.50$ & $19 \pm 0.80$ & $17 \pm 0.70$ \\
& Ampicillin/Ciprofloxacin & $10 \mu \mathrm{g} / \mathrm{ml}$ & $26.01 \pm 0.1$ & $24.02 \pm 0.05$ & $23 \pm 0.2$ \\
\cline { 2 - 6 } & Solvent control DMSO & - & 0.00 & 0.00 & 0.00 \\
\hline \multirow{3}{*}{ Leaves } & Methanol Extract & 50 & $11 \pm 0.50$ & $16 \pm 0.45$ & $17 \pm 0.50$ \\
\cline { 2 - 6 } & Acetone Extract & 50 & $09 \pm 0.50$ & $13 \pm 0.50$ & $14 \pm 0.40$ \\
& Aqueous Extract & 50 & $07 \pm 0.50$ & $08 \pm 0.45$ & $09 \pm 0.50$ \\
\cline { 2 - 6 } & Ampicillin/Ciprofloxacin & $10 \mu \mathrm{g} / \mathrm{ml}$ & $25.09 \pm 0.1$ & $23.02 \pm 0.05$ & $22.01 \pm 0.2$ \\
& Solvent control DMSO & - & 0.00 & 0.00 & 0.00 \\
\hline
\end{tabular}

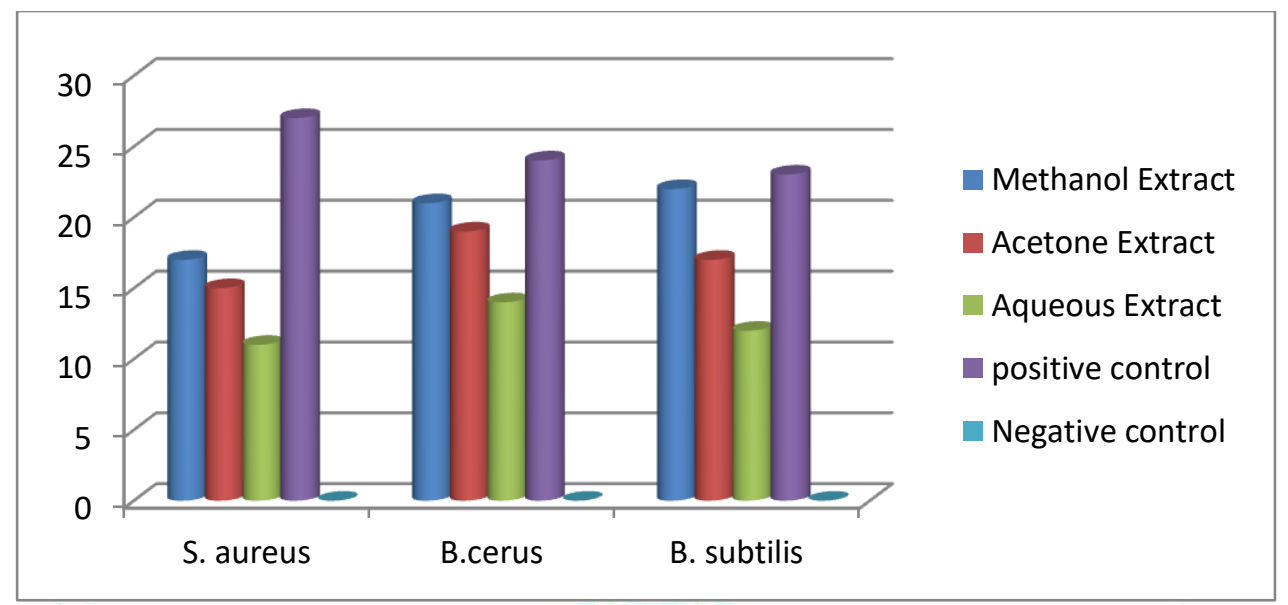

Figure:1 Comparison of Methanolic ,Acetone and Aqueous extract of Butea monosperma(Flower) against Bacterial Pathogen.

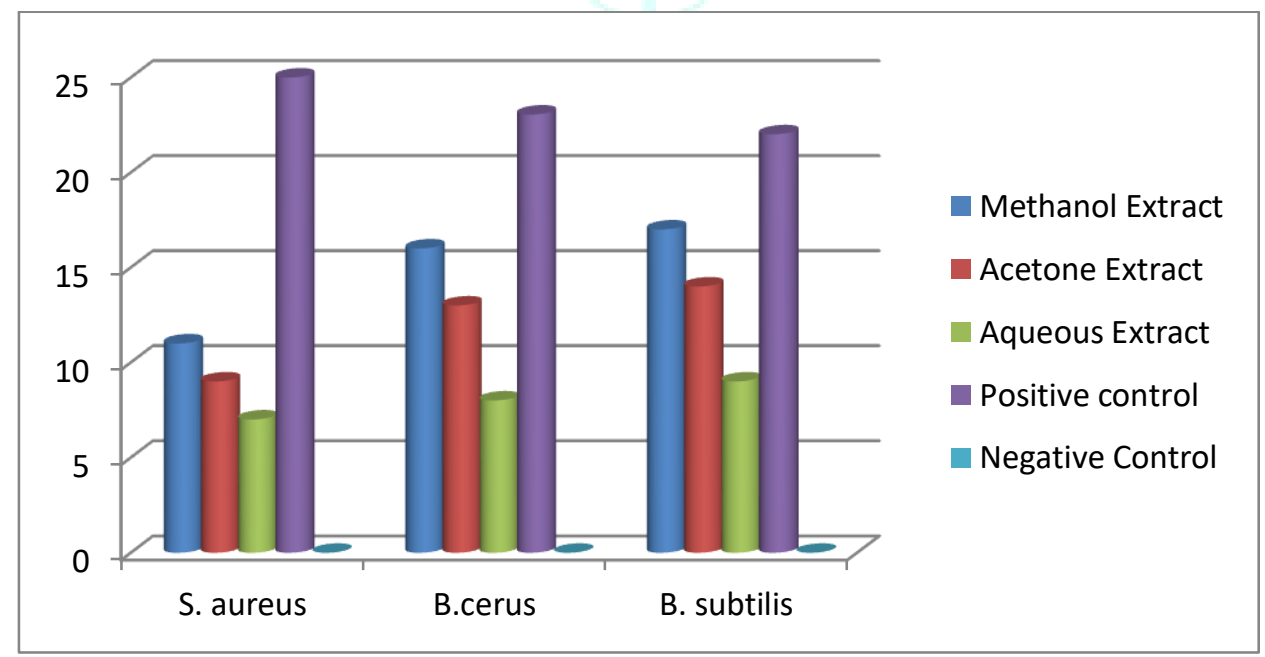

Figure:2 Comparison of Methanolic ,Acetone and Aqueous extract of Butea monosperma(Leaves) against Bacterial Pathogen.

Table 3: Antibacterial activity (AI and RPI) of Butea monosperma

\begin{tabular}{lccccccc}
\hline Extract & $\begin{array}{c}\text { Con. } \\
(\mathbf{m g} / \mathbf{m l})\end{array}$ & \multicolumn{2}{c}{ S. aureus } & \multicolumn{2}{c}{ B.cerus } & \multicolumn{2}{c}{ B. subtilis } \\
\hline & & AI & RPI & AI & RPI & AI & RPI \\
Leaves Methanol & 50 & 0.440 & 19.36 & 0.695 & 48.39 & 0.772 & 0.597 \\
Leaves Acetone & 50 & 0.360 & 12.96 & 0.567 & 31.94 & 0.636 & 0.404 \\
Leaves Water & 50 & 0.280 & 07.84 & 0.347 & 12.09 & 0.409 & 0.167 \\
Flower Methanol & 50 & 0.655 & 42.75 & 0.875 & 0.765 & 0.956 & 0.914 \\
Flower Acetone & 50 & 0.578 & 33.28 & 0.825 & 0.626 & 0.739 & 0.546 \\
Flower Water & 50 & 0.422 & 17.89 & 0.582 & 0.340 & 0.521 & 0.272 \\
\hline
\end{tabular}


The preliminary phytochemical analysis gives valuable information regarding the presence of important classes of phytochemicals present in the extracts of Butea monosperma. The outcomes of the qualitative phytochemical analysis of various extracts of leaves are given in Table 4. Various phytochemicals may play role as antimicrobial agent which were extracted in different solvents. These phytochemicals having antimicrobial activity should be identified and purified from the crude extracts by various analytical techniques and can be implicated in the development of antimicrobial drugs against various pathogenic microorganisms.

Table: 4 Phytochemical constituent analysis for extracts of Butea monosperma

\begin{tabular}{|ccc|}
\hline PARAMETERS & TEST & RESULT \\
\hline Test for Alkaloids & Dragendroff's reagent & + \\
& Mayer's reagent & + \\
\hline Test for Tannins & Wagner's reagent & + \\
& Lead acetate & + \\
\hline Test for flavonoids & Ferric chloride test & + \\
\hline Test for Saponins & Bromine water & + \\
\hline Test for Phenol & Ammonium test & + \\
\hline Test for glycosides & Froth Emulsion test & - \\
\hline Test for proteins & Ammonium hydroxide Test & + \\
\hline & Anthraquinone glycosides - & + \\
\hline Test for sugars & Borntranger test & + \\
\hline & Biuret & + \\
\hline
\end{tabular}

In conclusion, this study reports the presence of various phytochemical constituents such as alkaloids, tannins and phenolic compound in different solvent extracts (methanol, acetone, water) of Butea monosperma(Leaves and Flower). Among three extraction solvents methanol gives higher extraction yield for plants. Methanolic and acetonic extract from this plants offered a significant antimicrobial activity to test organism show ever methanolic extract from these plants showed comparative higher antimicrobial activity. In addition to this study further efforts including quantification, purification, detection of toxicity and side effects of antimicrobial compounds, may be required to strengthen potential this antimicrobial plant extract and favourable outcomes.

Acknowledgment: Authors would like to thank Mehsana Urban Institute of Sciences, Ganpat University, Gujarat, India, for providing facilities to carry out this research work.

\section{REFERENCES}

1. Divya fageria, Dr. D.V. Rao, A Review on Butea monosperma (Lam.) kuntze: A Great Therapeutic Valuable Leguminous Plant, International Journal of Scientific and Research Publications, 2015;5(6):1-9

2. M.V. Patil, S. Pawar and D.A. Patil. Ethnobotany of Butea monosperma (Lam.) Kuntze in North Maharashtra, India. Nat. Prod. Rad. 2006.p.: 323-25.

3. K. R. Kirtikar, B.D. Basu, Indian medicinal plants, $2^{\text {nd }}$ edition Lalit mohan Basu, Allahabad, India, 1935.p. 1-838.

4. L.D. Kapoor. Handbook of Ayurvedic Medicinal Plants, Herbal Reference Library Edition (Replica Press Pvt. Ltd., India, 2005.p. 1-86.

5. D. A. Burlia, A. B. Khade, A Comprehensive review on Butea monosperma (Lam.) Kuntze, Pharmacognosy Reviews,2007;1(2):94-99

6. M.S. Lavhale and S.H. Mishra. Evaluation of free radica scavenging activity of Butea monosperma Lam. Indian,J. Exp. Biol,2007;45: 376-84

7. Chandarana, H., S. Baluja and S. Chanda, Comparison of antibacterial activities of selected species of Zingeberaceae family and some synthetic compounds, Turk. J. Bio,2005; 29:8397.
8. Vaillant V, de Valk H, Baron E, Ancelle T, Colin P, Delmas MC, et al. Foodborne infections in France, Foodborne Pathog Dis, 2005;2:221-32.

9. Pooja Gupta, Naresh Chandra ,antibacterial study of butea monosperma (lamk.) Taub. Plant parts using agar well diffusion method, world journal of pharmacy and pharmaceutical sciences, 2016;5(10):1002-1010

10. Pranay Jain, Dinesh Bansal, and Pragya Bhasin, Antibacterial activity of aqueous plant extracts against Escherichia coli and Bacillus subtilis, DrugInvention Today 2009; 2(4):220222.

11. Kruti Dave, Hardik Shah, Kirankumar G. Patel, Antibacterial Activity and Phytochemical Analysis of Methanolic and Acetonic Extracts from Moringa oleifera, Vitex negundo and Rosa indica, International Journal of Current Microbiology and Applied Sciences,2018;7(7): 3718-3727

12. A. D. Olasupo, O. V. Olagoke, A. B. Aborisade, Qualitative Phytochemical Screening of Bologi (Senecio biafrae) and Bitter Leaf (Vernonia amygdalina) Leaves, Chemical Science International Journal,2017;20(3):1-6.

13. Prabhavathi R. M., Prasad M. P.Jayaramu M.Studies on Qualitative and Quantitative Phytochemical Analysis of Cissus quadrangularis, Advances in Applied Science Research, 2016, $7(4): 11-17$.

14. Darshan dharajiya,Hitesh jasani,Tarun khatrani, Manthan kapuria et.al, evaluation ofantibacterial and antifungal activity of fenugreek (trigonella foenum-graecum) extracts, International Journal of Pharmacy and Pharmaceutical Sciences,2016;8(4):212-217.

15. Dharajiya D, Patel P, Moitra N. Antibacterial activity of Emblica officinalis (Gaertn.) Fruits and Vitex negundo (L.) Leaves, Curr Trends Biotechnol Pharm, 2015;9:357-68.

16. Rubenice Amaral da Silva, Silvana Amado Liberio, Flavia M. M. do Amaral et.al, Antimicrobial and Antioxidant Activity of Anacardium occidentale L. Flowers in Comparison to Bark and Leaves Extracts,scientific Research,2016;4(4),457-462.

17. Mahesh Chandra Sahu, Rabindra Nath Padhy, In vitro antibacterial potency of Butea monosperma Lam. against 12 clinically isolated multidrug resistant bacteria, Asian Pacific Journal of Tropical Disease, 2013; 3(3): 217-226.

18. Dash BK, Sultana S, Sultana N. Antibacterial activities of methanol and acetone extracts of fenugreek (Trigonella foenum) and coriander (Coriandrum sativum),Life Sci Med Res, 2011;27:1-8. 